\title{
Usulan Perbaikan Lini Perakitan Box Speaker SWF PMA 9502 PT. HIT dengan Metode Ranked Positional Weight
}

\author{
Tita Talitha*1, Rekha Azzi Fahmi Farezi ${ }^{2}$ \\ ${ }^{1,2}$ Program Studi Teknik Industri, Fakultas Teknik, Universitas Dian Nuswantoro Semarang \\ Jl. Nakula I No. 5 - 11, Semarang \\ Telp. (024) 3555628, Fax (024) 3555628 \\ e-mail:*1titatalitha@gmail.com, ${ }^{2}$ rekhafarezi@gmail.com
}

\begin{abstract}
Abstrak
PT. Hartono Istana Teknologi (HIT) merupakan perusahaan yang bergerak di bidang industri elektronika yang lebih dikenal dengan nama "POLYTRON". Salah satu produk andalan dari perusahaan ini adalah Speaker SWF PMA 9502 yang sangat laku dikalangan konsumen. Menurut data output actual assembly box speaker SWF PMA 9502 dari tanggal 1 Agustus 2019 sampai 12 September 2019 memiliki rataan produksi 105 unit/jam, dimana target produksi yaitu 120 unit/jam. Tidak tercapainya target produksi perusahaan, disebabkan oleh tidak seimbangnya lini perakitan sehingga mengakibatkan bottleneck. Untuk itu perlu dilakukan perbaikan menggunakan metode Ranked Positional Weight (RPW). Metode ini digunakan sebagai pendekatan untuk membantu perusahaan dalam mengetahui seberapa efektif lini perakitan. Berdasarkan metode RPW dihasilkan waktu perakitan box speaker SWF PMA 9502 sebesar 396,31 detik, dari waktu semula sebesar 413,58 detik. Penerapan metode RPW juga dapat mengurangi balance delay sebesar 4,59\%.
\end{abstract}

Kata kunci: keseimbangan lini perakitan, bottleneck, produksi, balance delay

\begin{abstract}
PT. Hartono Istana Teknologi (HIT) is a company work on electronics manufacture industry, known as "POLYTRON". One of the products from this company is SWF PMA 9502 speaker which is popular on market. According to the actual output data of SWF PMA 9502 speaker box assembly from 1 August 2019 until 12 September 2019, it has an average production 105 units/hour, where the production target is 120 units/hour. Not achieving the production target of this company caused by inbalance assembly line, so that happens bottleneck. For this reason improvement needs to be done using Ranked Positional Weight $(R P W)$ method. The method is used as an approach to assist companies in knowing how effective assembly lines. Based on the RPW method, the assembly time of the SWF PMA 9502 speaker box is 396.31 seconds, which initially was 413.58 seconds. The application this method can also reduce the value of balance delay about $4.59 \%$.
\end{abstract}

Keywords: assembly line balancing, bottleneck, production, balance delay

\section{PENDAHULUAN}

Perkembangan industri manufaktur di Indonesia semakin pesat. Hal ini seiring dengan perkembangan teknologi yang semakin canggih. Banyak perusahaan bersaing untuk terus meningkatkan kualitas produknya dan juga memenuhi kebutuhan pelanggan agar mampu bersaing dengan perusahaan lainnya. Pemenuhan kebutuhan konsumen harus sesuai dengan waktu yang telah ditentukan. Persaingan di bidang elektronik saat ini semakin ketat, hal ini dikarenakan di tahun 2018 cenderung mengalami pertumbuhan yang minus atau turun sekitar $9,1 \%$ pada kuartal 
kedua tahun 2018. Maka dari itu banyak perusahaan yang bersaing untuk terus meningkatkan pertumbuhan penjualan dari produk mereka di tahun 2019 ini.

Guna meningkatkan pertumbuhan penjualan barang elektronik, maka dibutuhkan produk yang berkualitas baik dan juga efisiensi biaya produksi. Guna mendapatkan semua itu, maka perusahaan harus bisa memproduksi barang dengan kuantitas yang tepat, biaya yang tepat, dan juga ketepatan dalam pengiriman barang ke konsumen. Salah satu elemen penting dalam pemenuhan kebutuhan konsumen agar tepat waktu adalah lini perakitan. Maka dari itu, lini perakitan harus di desain dengan baik dan efektif.

PT. Hartono Istana Teknologi (HIT) ini berdiri di Kota Kudus, Jawa Tengah pada tanggal 16 Mei 1975. Perusahaan ini bergerak di bidang industri elektronika yang lebih dikenal dengan nama "POLYTRON". Salah satu produk andalan dari perusahaan ini adalah Speaker SWF PMA 9502 yang sangat laku di kalangan konsumen. Untuk mempertahankan posisi tersebut, maka perusahaan harus bisa memenuhi target produksi yang telah disesuaikan dengan permintan pasar. Salah satu faktor penting untuk bisa memenuhi target produksi adalah di bagian lini perakitan box mentah. Dimana dalam memenuhi target produksi diperlukan keseimbangan lini lintasan agar tidak terjadi penumpukan material di salah satu stasiun kerja / bottleneck (Afriana dan Suletra, 2017) .

Berdasarkan data dari SAP PT. HIT didapatkan data hasil lini perakitan box mentah SWF PMA 9502 per tanggal 1 Agustus 2019 - 12 September 2019 memiliki output 10269 box dengan total waktu assembly 5859 menit. Berdasarkan data tersebut, didapatkan output aktual per jam sebesar 105 box dengan waktu assembly per box sebesar 34,23 detik. Output aktual tersebut, masih dibawah target produksi perusahaan sebesar 120 box/jam. Hal tersebut terjadi karena pembagian job line assembly box mentah speaker SWF PMA 9502 yang tidak seimbang. Akibatnya perusahaan harus memberikan waktu lembur kepada para operator untuk dapat menyelesaikan target produksi pada hari itu, hal ini tentu menambah beban biaya produksi yang ditanggung perusahaan. Berdasarkan hasil pengamatan dalam proses assembly produk terdapat perbedaan antara cycle time stasiun kerja satu dengan lainnya, hal ini mengindikasikan adanya pembagian kerja yang tidak merata. Oleh sebab itu lintasan produksi yang ada saat ini perlu diseimbangkan supaya dapat mengurangi atau menghilangkan delay dan line menjadi lebih efektif dan efisien (Purnamasari dan Cahyana, 2015).

\section{METODE PENELITIAN}

Penelitian dilakukan pada PT. Hartono Istana Teknologi, yang berdiri di Kota Kudus, Jawa Tengah pada tanggal 16 Mei 1975. Perusahaan ini bergerak di bidang industri elektronika yang lebih di kenal dengan nama "POLYTRON". Salah satu produk andalan dari perusahaan ini adalah Speaker SWF PMA 9502 yang sangat laku di kalangan konsumen. Untuk mempertahankan posisi tersebut, maka perusahaan harus bisa memenuhi target produksi yang telah disesuaikan dengan permintan pasar. Salah satu faktor penting untuk bisa memenuhi target produksi adalah di bagian lini perakitan box mentah. Dimana dalam memenuhi target produksi diperlukan keseimbangan lini lintasan agar tidak terjadi penumpukan material di salah satu stasiun kerja (bottleneck). Akibat dari bottlencek dapat mempengaruhi output yang dihasilkan di bawah target pihak manajemen. 
Metode Ranked Positional Weights (RPW) merupakan metode gabungan antara metode large candidate rules dengan metode region approach (Helgeson dan Birnie, 1961). Metode RPW menggunakan pendekatan bobot posisi dari tiap elemen kerja. Bobot posisi merupakan perhitungan antara elemen kerja tersebut dengan posisi masing-masing. Data-data yang dibutuhkan untuk melakukan pengolahan data dalam rangka mencari penyelesaian masalah dengan metode ranked positional weight adalah:

1. Data elemen pekerjaan

Bagian dari proses keseluruhan pekerjaan dari perakitan. Kita menggambarkan $\mathrm{N}$ sebagai jumlah total dari elemen kerja yang dibutuhkan untuk melengkapi perakita dan I adalah jumlah elemen kerja I dalam proses. Catatan: $\mathrm{I} \leq \mathrm{i} \leq \mathrm{N}$

2. Stasiun Kerja

Merupakan tempat pada lini perakitan dimana proses perkaitan dilakukan. Setelah menentukan interval waktu siklus, maka jumlah stasiun kerja yang efisien dapat ditetapkan dengan rumus (Baroto, 2002).

3. Waktu Siklus (Data Pengamatan)

Waktu maksimal suatu produk diproses pada setiap stasiun kerja. (Heizer dan Render, 2006).

4. Waktu Normal

Waktu yang diperlukan untuk seorang operator terlatih dan memiliki ketrampilan rata-rata untuk melaksanakan suatu aktivitas dibawah kondisi dan tempo kerja normal (Sutalaksana et al, 1979).

5. Waktu Baku (Standard)

Waktu yang diperlukan oleh seorang pekerja yang memiliki kemampuan ratarata untuk menyelesaikan secara wajar suatu pekerjaan yang memiliki sistem kerja paling baik (Sutalaksana et al, 1979).

6. Precedence Diagram

Precedence Diagram merupakan gambaran dari urutan operasi serta ketergantungan atau peta proses operasi pada posisi horizontal, tanda inspeksi dihilangkan dan atributnya dilepaskan kecuali atribut waktu dan tanda panah (Ekoanindiyo dan Helmy, 2017).

7. Balance Delay

Balance delay merupakan selisih antara waktu stasiun kerja $\mathrm{WS}_{\mathrm{i}}$ dengan waktu siklus CT yang digunakan sebagai ukuran yang menyatakan ketidakseimbangan suatu lintasan produksi (Nataprawira, 2013).

\section{HASIL DAN PEMBAHASAN}

\subsection{Elemen Kerja}

Berdasarkan hasil pengamatan langsung pada bagian produksi pembuatan box speaker SWF PMA 9502 maka diperoleh data waktu operasi elemen kerja. Pengumpulan data yang dilakukan adalah data waktu pengerjaan dari setiap elemen kerja dengan 6 kali pencatatan. Waktu baku elemen kerja ditetapkan dengan memperhitungkan penyesuaian dan kelonggaran. Hasil penentuan waktu baku dari tiap elemen kerja ditunjukkan pada Tabel 1. Selain itu juga ditentukan syarat precedence diagram yang harus dipenuhi oleh tiap elemen kerja. Gambar 1 menunjukkan precedence diagram untuk proses pembuatan box speaker SWF PMA 9502 yang menunjukkan aturan pengurutan elemen kerja. 


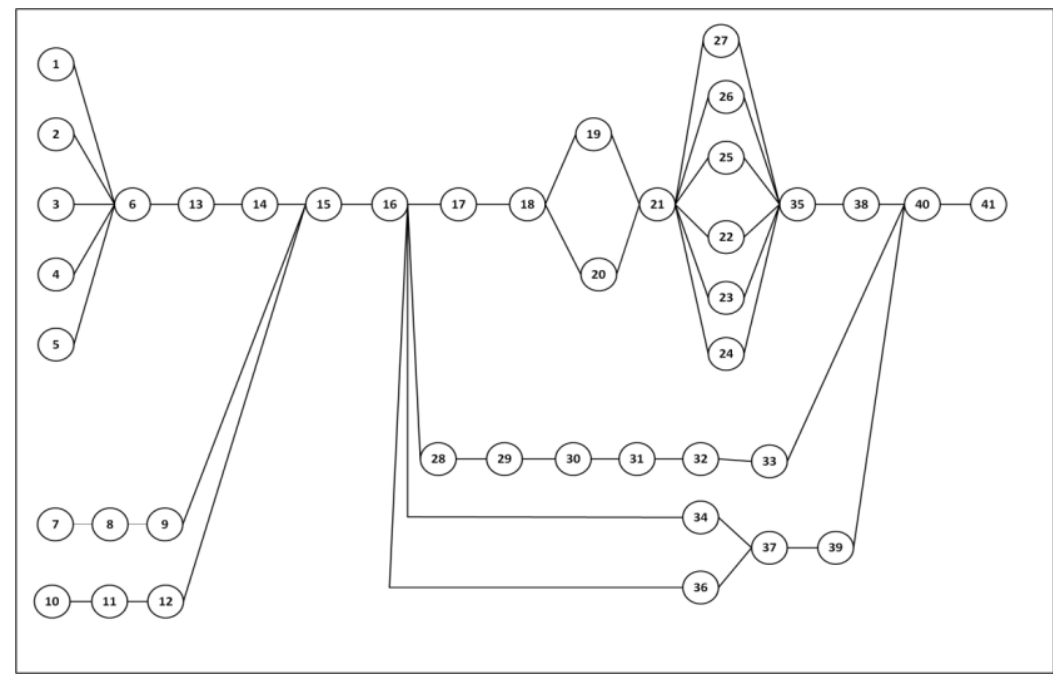

Gambar 1. Precedence diagram proses perakitan box speaker SWF PMA 9502

Tabel 1. Data waktu elemen kerja

\begin{tabular}{|c|c|c|c|c|c|}
\hline $\begin{array}{l}\text { Stasiun } \\
\text { Kerja }\end{array}$ & $\begin{array}{c}\text { Elemen } \\
\text { Kerja }\end{array}$ & Deskripsi Kerja & $\begin{array}{l}\text { Waktu } \\
\text { Siklus (s) }\end{array}$ & $\begin{array}{c}\text { Waktu } \\
\text { Baku } \\
\text { (s) }\end{array}$ & $\begin{array}{l}\text { Posisi } \\
\text { Kerja }\end{array}$ \\
\hline \multirow{6}{*}{1} & 1 & $\begin{array}{l}\text { Menata material side yang akan } \\
\text { diproses }\end{array}$ & 2,83 & 5,46 & Duduk \\
\hline & 2 & Meng-cutter bagian samping & 2,35 & 5,15 & Duduk \\
\hline & 3 & Memberi cat pada ujung v-cut & 5,24 & 9,79 & Duduk \\
\hline & 4 & Meng-cutter bagian lingkaran & 2,49 & 5,01 & Duduk \\
\hline & 5 & Menstaples side & 2,11 & 3,84 & Duduk \\
\hline & 6 & Menata side yang sudah diproses & 2,07 & 3,48 & Duduk \\
\hline Jumlah & & & 17,09 & 32,72 & \\
\hline \multirow{3}{*}{2} & 7 & $\begin{array}{l}\text { Mengambil material dan menata } \\
\text { pada jig }\end{array}$ & 4,14 & 7,59 & Duduk \\
\hline & 8 & $\begin{array}{l}\text { Menstaples material hingga } \\
\text { membentuk frame }\end{array}$ & 6,98 & 12,09 & Duduk \\
\hline & 9 & Menata frame yang sudah diproses & 1,36 & 3,43 & Duduk \\
\hline Jumlah & & & 12,47 & 23,11 & \\
\hline \multirow{3}{*}{3} & 10 & $\begin{array}{l}\text { Mengambil material dan menata } \\
\text { pada jig }\end{array}$ & 4,52 & 8,29 & Duduk \\
\hline & 11 & $\begin{array}{l}\text { Menstaple material hingga } \\
\text { membentuk frame }\end{array}$ & 6,71 & 11,62 & Duduk \\
\hline & 12 & Menata frame yang sudah diproses & 1,75 & 4,42 & Duduk \\
\hline Jumlah & & & 12,98 & 24,33 & \\
\hline \multirow{4}{*}{4} & 13 & Mengambil side & 1,41 & 3,63 & Duduk \\
\hline & 14 & $\begin{array}{l}\text { Memberi lem pada alur } \\
\text { yang ada di side }\end{array}$ & 8,78 & 15,48 & Duduk \\
\hline & 15 & $\begin{array}{l}\text { Mengambil frame dan menyatukan } \\
\text { side dan frame sampai berbentuk } \\
\text { kotak }\end{array}$ & 4,77 & 8,26 & Duduk \\
\hline & 16 & Memberi plakband & 3,96 & 10,31 & Duduk \\
\hline Jumlah & & & 18,92 & 37,68 & \\
\hline
\end{tabular}




\begin{tabular}{|c|c|c|c|c|c|}
\hline $\begin{array}{c}\text { Stasiun } \\
\text { Kerja }\end{array}$ & $\begin{array}{c}\text { Elemen } \\
\text { Kerja }\end{array}$ & Deskripsi Kerja & $\begin{array}{l}\text { Waktu } \\
\text { Siklus (s) }\end{array}$ & $\begin{array}{c}\text { Waktu } \\
\text { Baku } \\
\text { (s) }\end{array}$ & $\begin{array}{l}\text { Posisi } \\
\text { Kerja }\end{array}$ \\
\hline \multirow{3}{*}{5} & 17 & $\begin{array}{l}\text { Memberi lem di alur front pada } \\
\text { side }\end{array}$ & 11,59 & 22,09 & Berdiri \\
\hline & 18 & $\begin{array}{l}\text { Mengambil front dan memasang } \\
\text { pada side }\end{array}$ & 3,26 & 6,32 & Berdir \\
\hline & 19 & memberi plakband & 4,34 & 12,65 & Berdiri \\
\hline Jumlah & & & 19,19 & 41,06 & \\
\hline \multirow{3}{*}{6} & 20 & Memberi Plakband & 2,40 & 7,00 & Berdiri \\
\hline & 21 & $\begin{array}{l}\text { Memasang jig inject dan membalik } \\
\text { box }\end{array}$ & 7,35 & 13,22 & Berdiri \\
\hline & 22 & $\begin{array}{l}\text { Memasang Screw support dan } \\
\text { melepas jig inject }\end{array}$ & 8,80 & 15,75 & Berdiri \\
\hline Jumlah & & & 18,47 & 35,98 & \\
\hline \multirow{5}{*}{7} & 23 & Memasang Screw Support A & 3,44 & 8,09 & Berdiri \\
\hline & 24 & Memasang Screw Support B & 2,83 & 6,65 & Berdiri \\
\hline & 25 & Memasang Screw Support C & 2,78 & 6,53 & Berdiri \\
\hline & 26 & Memasang Screw support D & 3,19 & 7,49 & Berdiri \\
\hline & 27 & Memasang Screw Support E & 3,85 & 9,06 & Berdiri \\
\hline Jumlah & & & 16,09 & 37,82 & \\
\hline \multirow{4}{*}{8} & 28 & Memberi plak band & 2,26 & 6,59 & Berdiri \\
\hline & 29 & $\begin{array}{l}\text { Melepas plakband dari proses } \\
\text { sebelumnya }\end{array}$ & 2,92 & 9,03 & Berdiri \\
\hline & 30 & $\begin{array}{l}\text { Mengamplas di tempat yang } \\
\text { dilepas plakband }\end{array}$ & 4,66 & 8,39 & Berdiri \\
\hline & 31 & Memberi cat & 8,40 & 16,56 & Berdiri \\
\hline Jumlah & & & 18,24 & 40,57 & \\
\hline \multirow[t]{2}{*}{9} & 32 & $\begin{array}{l}\text { Menata jig dan memasang kaki- } \\
\text { kaki }\end{array}$ & 5,10 & 15,65 & Duduk \\
\hline & 33 & Memberi plakband & 4,22 & 7,11 & Duduk \\
\hline Jumlah & & & 9,31 & 22,77 & \\
\hline \multirow{2}{*}{10} & 34 & Memasang antivibration & 2,53 & 4,19 & Duduk \\
\hline & 35 & Mengelem alur & 17,17 & 39,95 & Duduk \\
\hline Jumlah & & & 19,70 & 44,14 & \\
\hline \multirow{2}{*}{11} & 36 & Memasang Antivibration & 5,01 & 8,31 & Duduk \\
\hline & 37 & Membersihkan/mengelap box & 16,03 & 26,80 & Duduk \\
\hline Jumlah & & & 21,04 & 35,11 & \\
\hline \multirow{4}{*}{12} & 38 & Membersihkan lem di dalam box & 5,51 & 10,39 & Duduk \\
\hline & 39 & Membersihkan bagian atas & 2,19 & 5,06 & Duduk \\
\hline & 40 & Memasang Inject front & 8,67 & 15,07 & Duduk \\
\hline & 41 & Menata Box pada pallet & 4,10 & 7,77 & Duduk \\
\hline Jumlah & & & 20,47 & 38,29 & \\
\hline Total W & aktu & & 203,97 & 413,58 & \\
\hline
\end{tabular}

\subsection{Analisis pada Kondisi Lintasan Aktual}

Berdasarkan pengamatan pada lintasan perakitan box speaker SWF PMA 9502 yang ada pada saat ini, perusahaan telah menerapkan pengelompokan elemen 
kerja ke dalam 12 stasiun kerja. Berikut merupakan perhitungan line balancing kondisi aktual. Efisiensi lintasan (EL) pada kondisi aktual, perhitungannya adalah sebagai berikut (Djunaidi dan Angga, 2017):

$$
\begin{aligned}
\text { Efisiensi Lintasan } & =\frac{\sum \text { Operation Time }}{\sum \text { Stasiun Kerja } \times \text { Max Stasiun Kerja }} \times 100 \% \\
& =\frac{413,58}{12 \times 44,14} \times 100 \% \\
& =78,08 \%
\end{aligned}
$$

Balance delay pada kondisi aktual, diperoleh hasil perhitungan sebagai berikut (Nataprawira, 2013):

Balance Delay $=\left(\sum\right.$ Stasiun Kerja $\times$ Max Stasiun Kerja $)-\sum$ Operation Time $\times 100 \%$

$$
\begin{aligned}
& =\frac{\sum \text { Stasiun Kerja } \times \text { Max Stasiun Kerja }}{12 \times 44,14} \times 100 \% \\
& =21,92 \%
\end{aligned}
$$

\subsection{Analisis pada Kondisi Lintasan Usulan Perbaikan}

Lintasan produksi perakitan box speaker SWF PMA 9502 dilakukan dengan menggunakan metode Ranked Position Weight (RPW). Pada usulan perbaikan lini perakitan ini, terdapat perubahan posisi kerja pada stasiun kerja ke 5, 6, 7, dan 8 yang semula dalam posisi kerja berdiri, diubah dengan posisi kerja duduk. Akibat adanya perubahan posisi kerja maka waktu baku untuk perakitan box speaker SWF PMA 9502 pun beruhah, hal ini bisa dilihat pada Tabel 2. Tabel 2 menunjukkan hasil perhitungan waktu baku usulan perbaikan. Setelah didapatkan waktu baku terbaru, bobot posisi dihitung berdasarkan akumulasi waktu elemen kerja dari elemen kerja tersebut dengan semua elemen kerja yang mengikuti, seperti telah ditentukan pada diagram precedence. Tabel 3 menunjukkan hasil perhitungan bobot posisi dari semua elemen kerja.

Selanjutnya dilakukan pengurutan elemen kerja berdasarkan bobot posisinya, dari elemen kerja yang bobot posisinya terbesar hingga yang bobot posisinya terkecil. Tabel 4 menunjukkan hasil pengurutan elemen kerja berdasar bobot posisi. Urutan elemen kerja berdasar bobot posisi yang dihasilkan akan digunakan sebagai dasar penentuan penugasan elemen kerja pada stasiun kerja. Penentuan jumlah stasiun kerja usulan yaitu berdasarkan urutan elemen kerja pada Ranked positional weight $(R P W)$ yang sudah diurutkan. Tabel 5 menunjukkan hasil penugasan elemen kerja pada tiap elemen kerja, dengan memperhatikan aturan urutan kerja berdasar diagram precedence dan total waktu layanan untuk tiap stasiun kerja.

Tabel 2. Hasil perhitungan waktu baku usulan perbaikan

\begin{tabular}{cccc}
\hline $\begin{array}{c}\text { Elemen } \\
\text { Kerja }\end{array}$ & $\begin{array}{c}\text { Waktu Siklus } \\
(\mathbf{s})\end{array}$ & $\begin{array}{c}\text { Waktu Normal } \\
(\mathbf{s})\end{array}$ & $\begin{array}{c}\text { Waktu Baku } \\
(\mathbf{s})\end{array}$ \\
\hline 1 & 2,83 & 4,2 & 5,46 \\
\hline 2 & 2,35 & 3,3 & 5,15 \\
\hline 3 & 5,24 & 7,54 & 9,79 \\
\hline 4 & 2,49 & 3,21 & 5,01 \\
\hline 5 & 2,11 & 2,96 & 3,84 \\
\hline 6 & 2,07 & 2,85 & 3,48 \\
\hline 7 & 4,14 & 5,85 & 7,59 \\
\hline
\end{tabular}




\begin{tabular}{|c|c|c|c|}
\hline $\begin{array}{l}\text { Elemen } \\
\text { Kerja }\end{array}$ & $\begin{array}{c}\text { Waktu Siklus } \\
\text { (s) }\end{array}$ & $\begin{array}{c}\text { Waktu Normal } \\
\text { (s) }\end{array}$ & $\begin{array}{c}\text { Waktu Baku } \\
\text { (s) }\end{array}$ \\
\hline 8 & 6,98 & 9,07 & 12,09 \\
\hline 9 & 1,36 & 2,81 & 3,43 \\
\hline 10 & 4,52 & 6,38 & 8,29 \\
\hline 11 & 6,71 & 8,72 & 11,62 \\
\hline 12 & 1,75 & 3,63 & 4,42 \\
\hline 13 & 1,41 & 2,97 & 3,63 \\
\hline 14 & 8,78 & 11,61 & 15,48 \\
\hline 15 & 4,77 & 6,19 & 8,26 \\
\hline 16 & 3,96 & 7,74 & 10,31 \\
\hline 17 & 11,59 & 14,8 & 19,74 \\
\hline 18 & 3,26 & 4,23 & 5,64 \\
\hline 19 & 4,34 & 8,47 & 11,3 \\
\hline 20 & 2,4 & 4,69 & 6,26 \\
\hline 21 & 7,35 & 9,12 & 11,85 \\
\hline 22 & 8,8 & 10,55 & 13,71 \\
\hline 23 & 3,44 & 5,42 & 7,23 \\
\hline 24 & 2,83 & 4,45 & 5,94 \\
\hline 25 & 2,78 & 4,38 & 5,84 \\
\hline 26 & 3,19 & 5,02 & 6,52 \\
\hline 27 & 3,85 & 6,07 & 7,88 \\
\hline 28 & 2,26 & 4,42 & 5,89 \\
\hline 29 & 2,92 & 6,05 & 8,06 \\
\hline 30 & 4,66 & 5,79 & 7,52 \\
\hline 31 & 8,4 & 11,09 & 14,79 \\
\hline 32 & 5,1 & 11,74 & 15,65 \\
\hline 33 & 4,22 & 5,34 & 7,11 \\
\hline 34 & 2,53 & 3,23 & 4,19 \\
\hline 35 & 17,17 & 30,76 & 39,95 \\
\hline 36 & 5,01 & 6,4 & 8,31 \\
\hline 37 & 16,03 & 20,1 & 26,8 \\
\hline 38 & 5,51 & 6,96 & 10,39 \\
\hline 39 & 2,19 & 3,74 & 5,06 \\
\hline 40 & 8,67 & 10,4 & 15,07 \\
\hline 41 & 4,1 & 5,75 & 7,77 \\
\hline
\end{tabular}

Tabel 3. Hasil perhitungan bobot posisi dari semua elemen kerja

\begin{tabular}{ccc}
\hline Elemen Kerja & Penjumlahan Jalur & Bobot Kerja \\
\hline 1 & $1,6,13,14,15,16,17,18,19,21,22,35,38,40,41$ & 182,02 \\
\hline 2 & $2,6,13,14,15,16,17,18,19,21,22,35,38,40,41$ & 182,08 \\
\hline 3 & $3,6,13,14,15,16,17,18,19,21,22,35,38,40,41$ & 186,72 \\
\hline 4 & $4,6,13,14,15,16,17,18,19,21,22,35,38,40,41$ & 181,94 \\
\hline
\end{tabular}




\begin{tabular}{|c|c|c|}
\hline Elemen Kerja & Penjumlahan Jalur & Bobot Kerja \\
\hline 5 & $5,6,13,14,15,16,17,18,19,21,22,35,38,40,41$ & 180,77 \\
\hline 6 & $6,13,14,15,16,17,18,19,21,22,35,38,40,41$ & 176,93 \\
\hline 7 & $7,8,9,15,16,17,18,19,21,22,35,38,40,41$ & 177,46 \\
\hline 8 & $8,9,15,16,17,18,19,21,22,35,38,40,41$ & 169,86 \\
\hline 9 & $9,15,16,17,18,19,21,22,35,38,40,41$ & 157,77 \\
\hline 10 & $10,11,12,15,16,17,18,19,21,22,35,38,40,41$ & 178,68 \\
\hline 11 & $11,12,15,16,17,18,19,21,22,35,38,40,41$ & 170,39 \\
\hline 12 & $12,15,16,17,18,19,21,22,35,38,40,41$ & 158,77 \\
\hline 13 & $13,14,15,16,17,18,19,21,22,35,38,40,41$ & 173,45 \\
\hline 14 & $14,15,16,17,18,19,21,22,35,38,40,41$ & 169,83 \\
\hline 15 & $15,16,17,18,19,21,22,35,38,40,41$ & 154,35 \\
\hline 16 & $16,17,18,19,21,22,35,38,40,41$ & 146,09 \\
\hline 17 & $17,18,19,22,35,38,40,41$ & 135,78 \\
\hline 18 & $18,20,22,35,38,40,41$ & 111 \\
\hline 19 & $19,21,22,35,38,40,41$ & 110,4 \\
\hline 20 & $20,21,22,35,38,40,41$ & 105,35 \\
\hline 21 & $21,22,35,38,40,41$ & 99,1 \\
\hline 22 & $22,35,38,40,41$ & 87,25 \\
\hline 23 & $23,35,38,40,41$ & 80,41 \\
\hline 24 & $24,35,38,40,41$ & 79,12 \\
\hline 25 & $25,35,38,40,41$ & 79,02 \\
\hline 26 & $26,35,38,40,41$ & 79,87 \\
\hline 27 & $27,35,38,40,41$ & 81,27 \\
\hline 28 & $28,29,30,31,32,33,40,41$ & 81,87 \\
\hline 29 & $29,30,31,32,33,40,41$ & 75,98 \\
\hline 30 & $30,31,32,33,40,41$ & 67,91 \\
\hline 31 & $31,32,33,40,41$ & 60,39 \\
\hline 32 & $32,33,40,41$ & 45,6 \\
\hline 33 & $33,40,41$ & 29,95 \\
\hline 34 & $34,37,39,40,41$ & 58,89 \\
\hline 35 & $35,38,40,41$ & 73,18 \\
\hline 36 & $36,37,39,40,41$ & 63,01 \\
\hline 37 & $37,39,40,41$ & 54,7 \\
\hline 38 & $38,40,41$ & 33,23 \\
\hline 39 & $39,40,41$ & 27,9 \\
\hline 40 & 40,41 & 22,84 \\
\hline 41 & 41 & 7,77 \\
\hline
\end{tabular}


Tabel 4. Hasil pengurutan nilai bobot posisi dengan metode RPW

\section{Rangking Elemen Kerja Bobot Kerja}

\begin{tabular}{|c|c|c|}
\hline 1 & 3 & 186,72 \\
\hline 2 & 1 & 182,02 \\
\hline 3 & 2 & 182,08 \\
\hline 4 & 4 & 181,94 \\
\hline 5 & 5 & 180,77 \\
\hline 6 & 10 & 178,68 \\
\hline 7 & 7 & 177,46 \\
\hline 8 & 6 & 176,93 \\
\hline 9 & 13 & 173,45 \\
\hline 10 & 11 & 170,39 \\
\hline 11 & 8 & 169,86 \\
\hline 12 & 14 & 169,83 \\
\hline 13 & 12 & 158,77 \\
\hline 14 & 9 & 157,77 \\
\hline 15 & 15 & 154,35 \\
\hline 16 & 16 & 146,09 \\
\hline 17 & 17 & 135,78 \\
\hline 18 & 18 & 111 \\
\hline 19 & 19 & 110,4 \\
\hline 20 & 20 & 105,35 \\
\hline 21 & 21 & 99,1 \\
\hline 22 & 22 & 87,25 \\
\hline 23 & 28 & 81,87 \\
\hline 24 & 27 & 81,27 \\
\hline 25 & 23 & 80,41 \\
\hline 26 & 26 & 79,87 \\
\hline 27 & 24 & 79,12 \\
\hline 28 & 25 & 79,02 \\
\hline 29 & 29 & 75,98 \\
\hline 30 & 35 & 73,18 \\
\hline 31 & 30 & 67,91 \\
\hline 32 & 36 & 63,01 \\
\hline 33 & 31 & 60,39 \\
\hline 34 & 34 & 58,89 \\
\hline 35 & 37 & 54,7 \\
\hline 36 & 32 & 45,6 \\
\hline 37 & 38 & 33,23 \\
\hline 38 & 33 & 29,95 \\
\hline 39 & 39 & 27,9 \\
\hline 40 & 40 & 22,84 \\
\hline 41 & 41 & 7,77 \\
\hline
\end{tabular}


Tabel 5. Urutan alokasi elemen kerja

\begin{tabular}{|c|c|c|c|}
\hline $\begin{array}{c}\text { Stasiun } \\
\text { Kerja }\end{array}$ & $\begin{array}{c}\text { Elemen } \\
\text { Kerja }\end{array}$ & $\begin{array}{c}\text { Waktu Baku } \\
\text { (s) }\end{array}$ & $\begin{array}{c}\text { Jumlah Waktu } \\
\text { (s) }\end{array}$ \\
\hline \multirow{6}{*}{1} & 3 & 9,79 & \multirow{6}{*}{32,72} \\
\hline & 1 & 5,46 & \\
\hline & 2 & 5,15 & \\
\hline & 4 & 5,01 & \\
\hline & 5 & 3,84 & \\
\hline & 6 & 3,48 & \\
\hline \multirow{3}{*}{2} & 7 & 7,59 & \multirow{3}{*}{23,11} \\
\hline & 8 & 12,09 & \\
\hline & 9 & 3,43 & \\
\hline \multirow{3}{*}{3} & 10 & 8,29 & \multirow{3}{*}{24,33} \\
\hline & 11 & 11,62 & \\
\hline & 12 & 4,42 & \\
\hline \multirow{4}{*}{4} & 13 & 3,63 & \multirow{4}{*}{37,68} \\
\hline & 14 & 15,48 & \\
\hline & 15 & 8,26 & \\
\hline & 16 & 10,31 & \\
\hline \multirow{4}{*}{5} & 17 & 19,74 & \multirow{4}{*}{37,88} \\
\hline & 18 & 5,64 & \\
\hline & 34 & 4,19 & \\
\hline & 36 & 8,31 & \\
\hline \multirow{4}{*}{6} & 19 & 11,3 & \multirow{4}{*}{36,63} \\
\hline & 20 & 6,26 & \\
\hline & 21 & 11,85 & \\
\hline & 23 & 7,23 & \\
\hline \multirow{5}{*}{7} & 22 & 13,71 & \multirow{5}{*}{39,88} \\
\hline & 24 & 5,94 & \\
\hline & 25 & 5,84 & \\
\hline & 26 & 6,52 & \\
\hline & 27 & 7,88 & \\
\hline \multirow{4}{*}{8} & 28 & 5,89 & \multirow{4}{*}{36,26} \\
\hline & 29 & 8,06 & \\
\hline & 30 & 7,52 & \\
\hline & 31 & 14,79 & \\
\hline 9 & 35 & 39,95 & 39,95 \\
\hline \multirow{3}{*}{10} & 32 & 15,65 & \multirow{3}{*}{33,16} \\
\hline & 33 & 7,11 & \\
\hline & 38 & 10,39 & \\
\hline \multirow{2}{*}{11} & 37 & 26,8 & \multirow[t]{2}{*}{31,86} \\
\hline & 39 & 5,06 & \\
\hline
\end{tabular}




\begin{tabular}{cccc}
\hline $\begin{array}{c}\text { Stasiun } \\
\text { Kerja }\end{array}$ & $\begin{array}{c}\text { Elemen } \\
\text { Kerja }\end{array}$ & $\begin{array}{c}\text { Waktu Baku } \\
(\mathbf{s})\end{array}$ & $\begin{array}{c}\text { Jumlah Waktu } \\
(\mathbf{s})\end{array}$ \\
\hline \multirow{2}{*}{12} & 40 & 15,07 & 22,84 \\
& 41 & 7,77 & \\
\hline & \multicolumn{2}{c}{ Total Waktu Baku } & $\mathbf{3 9 6 , 3 1}$ \\
\hline
\end{tabular}

Efisiensi lintasan (EL) pada kondisi usulan, diperoleh hasil sebagai berikut (Djunaidi dan Angga,2017):

$$
\begin{aligned}
\text { Efisiensi Lintasan } & =\frac{\sum \text { Operation Time }}{\sum \text { Stasiun Kerja } \times \text { Max Stasiun Kerja }} \times 100 \% \\
& =\frac{396,31}{12 \times 39,95} \times 100 \% \\
& =82,67 \%
\end{aligned}
$$

Balance Delay pada kondisi usulan, diperoleh hasil sebagai berikut (Nataprawira, 2013):

$$
\begin{aligned}
\text { Balance Delay } & =\frac{\left(\sum \text { Stasiun Kerja } \times \text { Max Stasiun Kerja }\right)-\sum \text { Operation Time }}{\sum \text { Stasiun Kerja } \times \text { Max Stasiun Kerja }} \times 100 \% \\
& =\frac{(12 \times 39,95)-396,31}{12 \times 39,95} \times 100 \% \\
& =17,33 \%
\end{aligned}
$$

\subsection{Perbandingan Hasil}

Berdasarkan atas perhitungan performansi pada kondisi aktual dan kondisi usulan dengan metode RPW di atas, maka dapat diketahui perbandingan pada kedua kondisi sehingga dapat diketahui kondisi yang memiliki nilai efisiensi lintasan terbesar. Hasil perbandingan dapat dilihat pada Tabel 6.

Dari Tabel 6, dapat dilihat bahwa lintasan perakitan masih sama yaitu 12 stasiun kerja. Akan tetapi, efisiensi lintasan perakitan dapat ditingkatkan dari 78,08\% menjadi $82,67 \%$ dan balance delay juga menurun dari $21,92 \%$ menjadi $17,33 \%$. Dengan peningkatan efisiensi lintasan tersebut, output produksi dapat ditingkatkan dari 105 unit/jam menjadi 109 unit/jam.

Tabel 6. Perbandingan hasil

\begin{tabular}{cccc}
\hline No. & Keseimbangan Lintasan & Aktual & Usulan \\
\hline 1 & Total Waktu (detik) & 413,58 & 396,31 \\
\hline 2 & Efisiensi Lintasan (\%) & 78,08 & 82,67 \\
\hline 3 & Balance Delay (\%) & 21,92 & 17,33 \\
\hline 4 & Output Perjam yang dihasilkan (unit) & 105 & 109 \\
\hline 5 & Waktu Per 1 Set Box Mentah (detik) & 34,46 & 33,02 \\
\hline 6 & Jumlah Stasiun Kerja & 12 & 12 \\
\hline
\end{tabular}

\section{KESIMPULAN}

Hasil dari rancangan pembagian job kerja yaitu jumlah stasiun kerja masih sama yaitu 12 stasiun kerja, akan tetapi waktu prosesnya berkurang yang awalnya 413,58 detik menjadi 396,31 detik. Hal tersebut menandakan bahwa adanya pengurangan waktu dalam proses assembly box speaker pada line assembly box speaker SWF PMA 9502, dimana hal tersebut juga akan berdampak pada 
bertambahnya jumlah output dari assembly box speaker SWF PMA 9502. Setelah dilakukan perhitungan menggunakan metode RPW, diperoleh balance delay 17,33\% dari yang awalnya sebesa21,92\% dan nilai efisiensi lintasan perakitan dapat ditingkatkan dari 78,08\% menjadi 82,67\%

\section{DAFTAR PUSTAKA}

Afriana, G. S. N. dan Suletra, I. W, 2017, Analisis Line Balancing dengan RPW pada Departemen Sewing Assembly Line Style F1625W404 di PT. Pan Brothers, Boyolali. Seminar dan Konferensi Nasional IDEC 2017.

Baroto, Teguh. 2002. Perencanaan dan Pengendalian Produksi. Jakarta: Ghalia Indonesia

Djunaidi, M. dan Angga, 2017. Analisis Keseimbangan Lintasan (Line Balancing) Pada Proses Perakitan Body Bus Pada Karoseri Guna Meningkatkan Efisiensi Lintasan. Jurnal Ilmiah Teknik Industri, Vol. 5, No. 2, 77 - 84

Ekoanindiyo, F. A.; Helmy, L., 2017. Meningkatkan Efisiensi Lintasan Kerja Menggunakan Metode Rpw Dan Killbridge-Western, Jurnal Dinamika Teknik,Vol. X, No. 1.

Heizer, Jay. dan Barry, Render, 2016, Operations Management (Buku 2 Edisi 7), Jakarta:Penerbit Salemba Empat

Helgeson, W.B; Birnie, D.P, 1961. Assembly Line Balancing sing the Ranked Positional Weighting Technique, Journal of Industrial Engineering, Vol.12, No. $1,18-27$.

Nataprawira, V.; Suhada, K., 2013, Perbaikan Lintasan Produksi dalam Upaya Mencapai Target Produksi dengan Menggunakan Metode Rank Positional Weight, Region Approach dan Algoritma Genetika (Studi Kasus di CV Surya Advertising and T-Shirt, Bandung), Jurnal Integra,Vol. 3, No. 1, 83- 102.

Purnamasari, I.; Cahyana, A.S., 2015, Line Balancing Dengan Metode Ranked Position Weight ( RPW), Spektrum Industri, Vol. 13, No. 2, 115 - 228.

Sutalaksana, I. Z., John H.Tjakraatmadja, dan Ruhana Anggawisastra, 1979, Teknik Tata Cara Kerja, Bandung : Penerbit Departemen Teknik Industri - ITB. 